\title{
INSTRUCCIONES PARA AUTORES
}

La revista HAMUT'AY es una publicación semestral de la División de Investigación y Extensión Científica Tecnológica de la Dirección Universitaria de Educación a Distancia de la Universidad Alas Peruanas cuyo objetivo es divulgar artículos científicos a texto completo sobre tecnologías y virtualidad y se dirige a la comunidad universitaria nacional e internacional.

Todos los artículos son sometidos a arbitraje a través de pares evaluadores nacionales e internacionales de amplia trayectoria en la línea temática de la revista. Los pares no son miembros del Comité Editorial ni de la institución editora.

Los artículos que se remiten a la revista deben ser originales e inéditos, no se enviaron a otra revista para su publicación y no han sido publicados.

\section{TIPOS DE ARTÍCULOS A PUBLICAR}

La revista acepta tres categorías de artículos.

Artículos de investigación científica y tecnológica (López, 2013, Publindex, 2010). Son investigaciones originales que presentan resultados de uno o varios proyectos de investigación académico-tecnológica concluidos o en proceso.

Artículos de revisión (Fernández-Ríos y Buela-Casal 2009). Son síntesis de estudios bibliográficos de un tema determinado, en el que se analiza, sintetiza y discute la información publicada de una manera integrada.

Reportes de Casos (Publindex, 2010). Son presentaciones de resultados de un estudio de caso sobre una situación específica, que da a conocer las experiencias técnicas y metodológicas consideradas en el caso.

\section{ESTRUCTURA DE LOS TIPOS DE ARTÍCULOS}

Todos los artículos deberán ser redactados con el programa Microsoft Word, usando las siguientes normas de estilo de la revista digital: tamaño pa- pel A4 con márgen izquierdo de $3 \mathrm{~cm}$. y $2.5 \mathrm{~cm}$. en los demás márgenes; fuente Times New Román, tamaño 12 e interlineado a doble espacio.

En el encabezado deberá ir el título del artículo y los nombres completos de los autores, según el orden de participación. Cada una de las páginas del artículo debe estar numerada consecutivamente.

\section{Composición de los tipos de artículos}

Los artículos de investigación científica y tecnológica (López, 2013; Bobenrieth, 2002). Se componen del título, autor(es), resumen (abstract), palabras claves (keywords), introducción (objetivos), materiales y método (participantes, instrumento, diseño, procedimiento), resultados (interpretación tablas y figuras), discusión y conclusiones, referencias bibliográficas y agradecimientos y anexos (opcional). EFACYT.

Los artículos de revisión (Fernández-Ríos y Buela-Casal 2009, p.332). Están compuestos del título, autor(es), resumen (abstract), palabras claves (keywords), introducción, método (criterios de selección de la literatura) y revisión de la literatura (marco teórico del tema de revisión). EFAR

Tablas: El título será claro, conciso y descriptivo del contenido de la tabla. Solo la palabra inicial lleva mayúsculas y no se coloca punto al final del título. Veáse modelo siguiente:

\begin{tabular}{lcc}
$\begin{array}{l}\text { Herramientas de } \\
\text { virtualización }\end{array}$ & Tiempo (s) & CPU (\%) \\
\hline Xen & 109 & 35,14 \\
VirtualBox & 87 & 82,88
\end{tabular}

Tabla 1. Tiempo transcurrido de arranque y consumo de CPU de las herramientas de virtualización

En el contenido de la tabla las fracciones decimales se expresarán con una coma, excepto en el Abstract donde se usará el punto. Las cifras en miles y millones se separarán con un espacio simple, en vez de comas.

Figuras: Son gráficas, fotografías, diagramas y dibujos en formato JPG de calidad alta. El título 
será breve y conciso. Veáse el siguiente ejemplo.

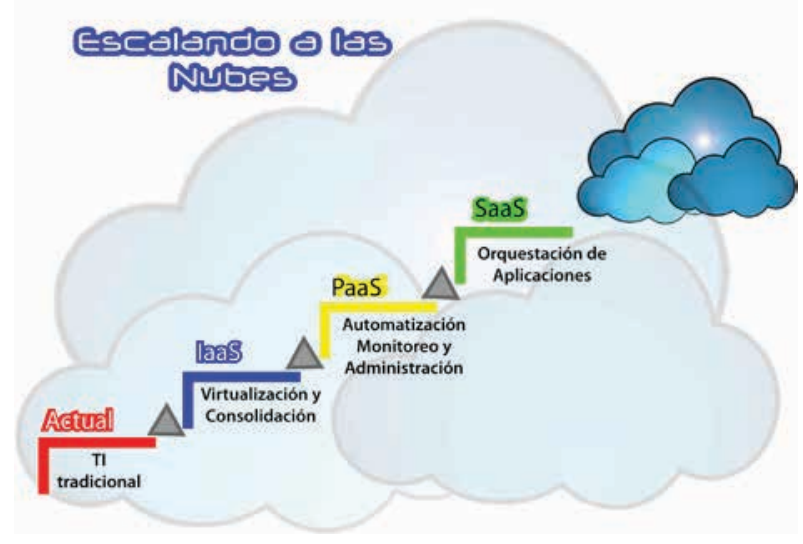

Figura 1. Escalando a las nubes.

Fuente: http://www.eikonix.mx/?page_id=113

Referencias bibliográficas. Las referencias y citas bibliográficas deberán considerar las Normas APA, Sexta Edición. Veáse los siguientes ejemplos:

\section{Articulos publicados en revistas:}

Cabero, J. (2010). Los retos de la integración de las TICs en los procesos educativos: Limites y pósibilidades, Rev Perspectiva Educacional, 49 (1), 36-61

\section{Libros:}

Cabello, R. \& Levis, D. (2007), Medios informáticos en la educación a principios del siglo XXI, (p.107) 1era. Edición. Argentina: Publicaciones Prometeo Libros

\section{Capitulos de libros:}

García, A., Cocero, D., Velázquez, J., Blanco, E., Grande, M., Núñez, M.V. \& Tejera, R. Aplicación de la teledetección a la gestión silvopastoral (2006). En Camacho Olmedo, M., Cañete, J. \& Lara, J. El acceso a la información espacial y las tecnologías geográficas. (pp.831-842). España Granada: Editorial universidad de Granada

\section{Tesis:}

Carmona, J. (2012) Aplicaciones de la simulación tridimensional para la detección precoz de consumo de sustancias y violencia escolar en ámbitos educativos entre los ańos 2011 y 2012. Tesis doctoral, Universidad de Almería, Almería, España

\section{Páginas electrónicas:}

Fernandez-Rios \& Buela-Casal, G. (2009) Standars for the preparation and writing of psicholo- gy, Internacional Journal of Clinical and Health Psychology (citado el 15 de febrero del 2014), 9 (2), 329-344. Recuperado de http://www.aepc.es/ ijchp/ref-es-326.pdf

\section{ENVÍO DE ARTÍCULOS}

Los autores enviarán el artículo científico acompañado de la declaración jurada de autoría y autorización (DEJA) al Editor jefe de la revista (Dra. Cleofé Genoveva Alvites Huamaní <revistahamutay@uap.edu.pe>. Los autores recibirán confirmación de la fecha de recepción de su trabajo.

\section{PROCESO DE EVALUACIÓN DE ARTÍCULOS}

La evaluación de los artículos tiene dos fases:

Primera fase: El grupo editorial verifica el cumplimiento de los aspectos estructurales y de forma según las indicaciones para autores, en los formatos establecidos, y de acuerdo al tipo de artículo.

Segunda fase: Los árbitros (pares revisores) determinan el valor del contenido del artículo y sus aspectos metodológicos, evaluando la calidad científica del artículo. Los pares evaluadores emiten uno de los siguientes criterios: No publica, Publica con condición (levantará observaciones previa a la publicación) y publica, considerando para ello los criterios estipulados en el PEAR o PEAO o PEEC, según sea el caso. Si se da el criterio de Publica con condición se remitirá al autor para que levante las observaciones, luego éste devolverá a l editor para que lo envíe al par revisor para su arbitraje.

\section{REFERENCIAS BIBLIOGRÁFICAS}

Bobenrieth, M. (2002) Normas para revisión de artículos originales en Ciencias de la Salud. Revista Internacional de Psicología Clínica y de la Salud, 2 (4) 509-523.

Fernandez-Ríos, L. y Buela-Casal, G. (2009) Standards for the preparation and writin of Psychology review articles. Revista International Journal of Clinical and Health Psychology, 9 (2) 329-344.

López, S. (2013) El proceso de escritura y publicación de un artículo científico. Revista Electrónica Educare, 17 (1), 5-27. Recuperado de http://www.revistas.una.ac.cr/index. php/EDUCARE/issue/current. 
Romani, F. (2010) Reporte de caso y serie de casos: una aproximación para el pregrado. Revista CIMEL 15 (1), 46-51 recuperado de http://www.redalyc.org/articulo. oa?id=71720941013.

Publindex (2010) Documento Guía, servicio permanente de indexación de Revistas de Ciencia, Tecnología e innovación Colombianas, Base Bibliográfica Nacional-BBN, Índice bibliográfico nacional Publindex-IBN. 